\title{
Innovative Oral Treatments of Uterine Leiomyoma
}

\author{
Mohamed Sabry ${ }^{1,2}$ and Ayman Al-Hendy ${ }^{3}$ \\ ${ }^{1}$ Center for Women Health Research (CWHR), Meharry Medical College, Nashville, TN 37208, USA \\ ${ }^{2}$ OB/GYN Department, Faculty of Medicine, Sohag University, Sohag 82524, Egypt \\ ${ }^{3}$ Center for Women Health Research, Department of Obstetrics and Gynecology, Meharry Medical College, George Hubbard Hospital, \\ 1005 Dr. D.B. Todd Jr. Blvd, 5th Floor, Room 5131C, Nashville, TN 37208, USA
}

Correspondence should be addressed to Ayman Al-Hendy, ahendy@mmc.edu

Received 17 August 2011; Accepted 31 October 2011

Academic Editor: Horace Fletcher

Copyright (C) 2012 M. Sabry and A. Al-Hendy. This is an open access article distributed under the Creative Commons Attribution License, which permits unrestricted use, distribution, and reproduction in any medium, provided the original work is properly cited.

\begin{abstract}
Uterine fibroids (leiomyoma), the benign tumors of the uterine wall, are very common cause of morbidity in reproductive age women usually in the form of excessive vaginal bleeding, chronic pelvic pain, miscarriage and infertility. These tumors are the leading indication for hysterectomy in the United States. Uterine fibroids are about 4 times higher in blacks compared to whites and constitute a major health disparity challenge. The estimated cost of uterine fibroids is up to $\$ 34.4$ billion annually. Additionally, women who suffer from this disease and desire to maintain their future fertility have very limited treatment choices. Currently, there is no effective long-term medicinal treatment for uterine fibroids. While surgery has traditionally been the gold standard for the treatment of uterine fibroids, there is growing interest towards orally administered medications for the management of leiomyoma-related symptoms. In this review, we will discuss these promising innovative oral medical treatments in detail.
\end{abstract}

\section{Introduction}

Uterine leiomyomas are the most common benign pelvic tumors in women $[1,2]$. They are monoclonal tumors of the smooth muscle cells of the myometrium and consist of large amounts of extracellular matrix that contain collagen, fibronectin and, proteoglycan [2,3]. A thin pseudocapsule that is composed of areolar tissue and compressed muscle fibers usually surrounds the tumors [4]. Leiomyomas may enlarge to cause significant distortion of the uterine surface or cavity. Dark skinned women, such as African Americans, also had higher numbers of leiomyomas and tended to have larger uteri, which in turn may explain the higher incidence of in-hospital complications or blood transfusion requirements in AA women compared to white women $[5,6]$. The overall incidence of uterine leiomyomas is estimated to be 3-4 times higher in African American women compared to Caucasian women [7-10]. Recent data have also confirmed that the age-standardized rates of ultrasound- or hysterectomy-confirmed leiomyoma were significantly higher in black women compared to white women [11]. Although they are benign, they commonly result in severe symptoms, such as heavy, irregular, and prolonged menstrual bleeding as well as anemia. Uterine leiomyomas have also been associated with numerous other medical disorders, such as infertility, recurrent abortion, and preterm labor [12]. These clinical complications negatively impact women's health. Uterine leiomyomas are the most cited indication for the more than 600,000 hysterectomies that are performed in the US annually, and this major surgery is associated with morbidity and mortality as well as a huge economic impact on healthcare delivery systems that is estimated to be approximately $\$ 34.4$ billion/year [13] (Table 2).

\section{Current Treatment Options for Uterine Leiomyomas}

Treatment options for leiomyoma vary; treatment strategies are typically individualized based on the severity of the symptoms, the size and location of the leiomyoma lesions, the patient's age and their chronological proximity to menopause, and the patient's desire for future fertility. The usual goal of therapy is the relief of the symptoms (Table 1). The treatment options range from the use of acupuncture (ancient Chinese method) to the total removal of the uterus and 
TABLE 1: The clinical presentation of uterine leiomyomas.

(i) Asymptomatic

(ii) Abnormal uterine bleeding

(a) Menorrhagia

(b) Anemia

(iii) Pelvic pressure

(a) Urinary frequency

(b) Urinary incontinence

(c) Difficulty with urination

(d) Hydronephrosis

(e) Constipation

(f) Tenesmus

(iv) Pelvic mass

(v) Pelvic pain

(vi) Infertility

(vii) Obstetric complications

(viii) Pregnancy related

(a) Myoma growth

(b) Red degeneration and pain

(c) Spontaneous miscarriage

(ix) Malignancy

(x) Rare associations

(a) Ascites

(b) Polycythemia

(c) Familial syndromes, renal cell carcinoma

(xi) Benign metastasizing

its myoma contents (hysterectomy) [14]. To date, there is no definitive oral therapeutic agent for the treatment of uterine leiomyomas, which is a reflection of the remarkable lack of randomized clinical trial data that demonstrate the effectiveness and safety of medical therapies in the management of symptomatic leiomyomas [15].

\section{Oral Medical Agents for the Treatment of Uterine Leiomyomas}

Currently, there are no definitive FDA-approved agents for the oral medical treatment of uterine fibroids. However, there are several candidate agents that can be used in addition to other approaches in the management of this common benign tumor.

However, there are several candidate agents that can be used with varying degrees of success. Increasing knowledge of the mechanism of action of more recent candidate agents such as Vitamin D, Green tea extract, and Elagolix (oral $\mathrm{GnRH}$ antagonist) as well as that of older agents such as selective estrogen receptor modulators (SERMs), antiprogestins, aromatase inhibitors, cabergoline, danazol, and gestrinone may lead to the development of an oral agent with the ability to shrink leiomyoma size with minimal side effects.

This consequently will be discussed.

3.1. Vitamin D (VitD). Data from our laboratory demonstrate that Vitamin D (VitD) is an antifibrotic factor and
TABLE 2: Diagnosis of uterine leiomyoma.

(i) Pelvic examination: enlarged, irregular, firm, nontender uterus (ii) Ultrasound: transvaginal ultrasound, hypoechoic, heterogenous masses

(iii) Saline sonohysterography: for submucous fibroids or polypi

(iv) MRI: best method for exact mapping, numbering of fibroids

(v) Hysteroscopy: diagnosis of submucous fibroids

inhibits growth and induces apoptosis in cultured human leiomyoma cells through the downregulation of PCNA, CDK1, and BCL-2 and suppresses COMT expression and activity in human leiomyoma cells [16-18]. We have also recently demonstrated similar effects in the Eker rat model of uterine fibroids [19]. Another group in Finland demonstrated that Vitamin D inhibits growth of both myometrial and leiomyoma cells in vitro [20]. The growth inhibition was concentration dependent and the level of inhibition was statistically significant with the concentration of $1000 \mathrm{nM}$.

In a separate study from our group, the correlation between low serum levels of VitD and the increased risk of having symptomatic uterine fibroids were evaluated [21, 22]. We measured both the biologically active 1, 25 dihydroxyvitamin D3 and the precursor 25-hydroxyvitamin D3 in the serum from African American and white women with fibroids as well as normal healthy controls. Interestingly, then observed that 1,25 dihydroxyvitamin D3 is significantly lower in women with fibroids compared to normal healthy controls; additionally, there have been detected lower levels of total serum 25-hydroxyvitamin D3 in women with fibroids compared to healthy controls. These findings were observed both in African American women and in Caucasian women.

The aim of the study was to determine whether serum levels of VitD correlated with disease severity in women with symptomatic uterine fibroids. The study population consisted of 67 patients who had detailed repeated pelvic ultrasound evaluations over a 2 -year period with specific measurements of the total uterine volume and the volume of the individual leiomyoma lesions. The patients also had detailed laboratory analysis including serum 25 hydroxy Vit D3 levels. As shown in (Figure 1), a statistically significant negative correlation between the low serum VitD levels and the total uterine leiomyoma volume $(P<.05)$ as well as the number of leiomyoma lesions/uterus $(P<.05)$ was detected [23]. Taken together, our preliminary results suggest a strong dose-response correlation between lower serum VitD levels and increased severity of uterine fibroids. This presents an opportunity for the potential use of VitD or its potent analogues as novel treatment options or for the prevention of uterine fibroids.

To date no randomized controlled trials had been implemented to prospectively assess the efficacy of VitD in the management of uterine fibroids.

\section{Epigallocatechin Gallate (EGCG): Green Tea Extract}

Tea is one of the most widely consumed beverages all over the world. Both the green tea and the black tea are derived from 


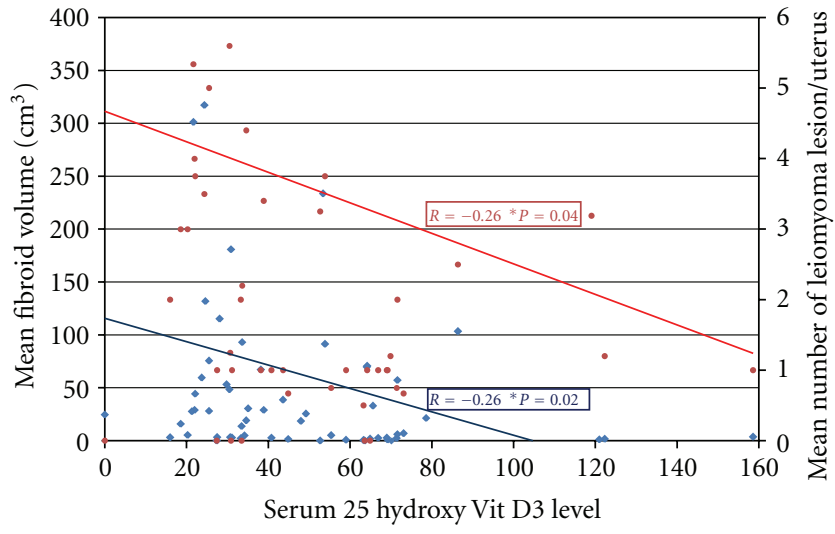

- Mean leiomyoma volume $\left(\mathrm{cm}^{3}\right) /$ patient

— Linear (mean leiomyoma volume $\left(\mathrm{cm}^{3}\right) /$ patient)

- Mean leiomyoma number/patient

— Linear (mean leiomyoma number/patient)

Figure 1: Serum Vitamin D3 level (nmol/L) inversely correlates with both mean volume and number of uterine fibroids.

the leaves of the plant "Camellia sinensis", the most signficant components of which are phytochemicals, of which Green tea is thoroughly studied for its health benefits.

A typical green tea beverage, prepared in a proportion of $1 \mathrm{~g}$ leaf to $100 \mathrm{~mL}$ water in a 3-min, brew, usually contains $250-350 \mathrm{mg}$ tea solids, and catechins account for $30-42 \%$ of the dry weight of the solids [24]. It has been demonstrated that tea constituents exhibit various biological and pharmacological properties such as anticarcinogenic, antioxidative, antiallergic, antivirus, antihypertensive, antiatherosclerosis, anticardiovascular disease and antihypercholesterolemic activities $[25,26]$.

The major green tea catechins are epigallocatechin-3gallate (EGCG), epigallocatechin (EGC), epicatechin-3-gallate (ECG), and epicatechin. Catechins are a group of bioflavonoids that exhibit antioxidant and anti-inflammatory capacity. Chemically, catechins are polyhydroxylated with water-soluble characteristics [27]. Epigallocatechin gallate (EGCG), which is the principal catechin, comprises $>40 \%$ of the total polyphenolic mixture of green tea catechins [28]. Grapes also contain polyphenols and catechins such as EGCG [29]. Epigallocatechin gallate exhibits various biological activities including potent antioxidant and anti-inflammation capacity [30].

EGCG appears to block each stage of tumorgenesis by modulating signaling pathways involved in cell proliferation, transformation, inflammation, and oxidative stress, which are clearly involved in pathogenesis of various tumors including uterine fibroids [31]. In our laboratory, the effect and potential mechanisms of EGCG action on human leiomyoma (HuLM) cells [32] were studied: cell proliferation and apoptosis were assayed; the protein levels of PCNA, CDK4, BCL2, and BAX were examined by Western blot analysis, and it was found that EGCG inhibits the proliferation of HuLM cells and induces apoptosis. These results suggest that EGCG may be a potential anti-uterine fibroid agent acting through multiple signal transduction pathways [33].
Additional validation of these findings was achieved using orally administered EGCG to shrink preexisting subcutaneous leiomyoma lesions in immune-compromised mice [32]. Previous studies have shown that EGCG inhibited the growth of various human cancer cells, such as epidermoid carcinoma cells [34], hepatoma cells [35], prostate carcinoma cells [36], and breast cancer cells [37]. Those findings motivated us to initiate a currently ongoing double-blind placebo-controlled clinical trial (phase II trial) to evaluate the promising clinical role of EGCG in women with symptomatic uterine fibroids.

\section{GnRH Antagonists}

The 3rd-generation GnRH antagonists display a more tolerable side effect profile compared to the first-generation $\mathrm{GnRH}$ antagonists (histamine release and severe allergic reactions) and the second generation GnRH antagonists (allergy and gel formation); some of the GnRH antagonists approved for clinical use by the US FDA include cetrorelix (Cetrotide; Serono) and ganirelix (Antagon; Organon International). These agents are usually used as injectables. GnRH antagonists exert their action through the direct competitive inhibition of GnRH by occupying the pituitary GnRH receptors and therefore blocking the access of the endogenous GnRH and exogenously administered agonists to their receptor sites $[38,39]$. These agents may induce a deep suppression of gonadotropins and the sex steroids, while avoiding any "flare up" phenomena, which may lead to a reduction in uterine fibroids size of up to 50\% [40]. One of the major limitations to the wide use of the GnRH antagonists in leiomyoma treatment is the short half-life of these agents and the non-availability of the Depot formulation, thus require repetitive dosing (daily for most of the antagonists) [41].

5.1. Promising GnRH Antagonist (Elagolix). Elagolix is a second-generation new nonpeptide $(\mathrm{GnRH})$ antagonist, highly potent antagonist orally active and rapidly bioavailable after administration that is being developed by Abbott Laboratories (Abbott) in collaboration with Neurocrine Biosciences $[42,43]$. It is finalizing the Phase III for endometriosis and finalizing Phase II for uterine leiomyoma with opportunity to be its first and only approved oral treatment for uterine leiomyoma [44]. This promising compound inhibits gonadotropin releasing hormone $(\mathrm{GnRH})$ receptors in the pituitary gland leading to a dose-dependent suppression of $\mathrm{LH}$, $\mathrm{FSH}$, and estradiol. Consequently, suppression of E2 is more prolonged at higher doses [45]. Pituitary suppression is maintained for only a portion of the day, and baseline gonadotropin levels return by 24 hours [46].

These properties suggest that Elagolix may enable doserelated pituitary and gonadal suppression in premenopausal women as part of treatment strategies for reproductive hormone-dependent disease states [46]. To date, Elagolix has been studied in 18 clinical trials totaling more than 1,000 subjects.

Elagolix seems to be well tolerated for multipledoses up to 200; rapidly absorbed after oral administration, with 
median time of maximum plasma concentration (Tmax) values ranging from 0.5 to $1 \mathrm{~h}$, the primary metabolite (NBI61962) appears in the serum rapidly after administration [46].

The therapeutic window of E2 levels for suppression of endometriosis is attainable at a dose of 100-150 mg/day with serum estradiol remained between 20 and $50 \mathrm{pg} / \mathrm{mL}$ [45]. This is supported by Barberi RL findings which showed that E2 levels between 30 and $50 \mathrm{pg} / \mathrm{mL}$ are effective in inducing endometrial atrophy [47]. The Elagolix therapeutic dose for management of uterine fibroid is yet to be determined.

\section{Selective Estrogen Receptor Modulator (SERMs)}

Selective estrogen receptor modulators (SERMs) are nonsteroidal estrogen receptor ligands that display tissue-specific agonist-antagonist estrogenic actions. They are used frequently in the treatment and prevention of estrogen receptor-positive carcinoma of the breast in addition to their use as ovulation induction agents $[48,49]$. Tamoxifen is one of the oldest known SERMs, but it may potentially cause endometrial carcinoma due to its partial agonistic effect on the endometrium [50]. There are no randomized controlled trials that have investigated the potential role of Tamoxifen in the treatment of uterine fibroids; however, a few case reports have suggested that it actually increases leiomyoma growth $[48,51]$. Raloxifene is another SERM that can be theoretically considered to be a candidate therapeutic option for uterine fibroids. Raloxifene only slightly affected collagen biosynthesis in control myometrium cells; however, it significantly inhibited collagen biosynthesis in leiomyoma cells [52] and exerted its action at the transcriptional level [53]. A newly developed SERM, "Lasofoxifene", is currently awaiting FDA approval. However, the results of early trials suggest that there were no significant benefits compared to raloxifene for the skeleton, breast, heart, or reproductive tract $[54,55]$.

6.1. Mechanism of Action. The most probable hypothesis that explains SERMs' mechanism of action is that they induce changes in estrogen receptors, which result in differential expression of specific estrogen-regulated genes in different tissues [56]. Every member of the SERM family has its own individual characteristics, which depend on its structure, the type of estrogen receptor they bind to, and the set of molecules that interact with its estrogen receptor/SERM complex in affected cells, and these characteristics result in either agonistic or antagonistic activity [57]. SERMs could potentially provide therapeutic benefits by having antagonistic effects at uterine myometrial level and by preventing ovarian stimulation which has been achieved in rat studies. The difference in activity of SERMs is based on the structure activity relationships (SARs) [58].

6.2. SERMs and Treatment of Uterine Fibroids. All SERMs, with their estrogen blocking activity, would be theoretically expected to exert at least some therapeutic effect on uterine fibroids. Raloxifene has been shown to enhance the shrinkage of uterine fibroids in postmenopausal women $[59,60]$. However, a recent report from Italy that addressed the effect of raloxifene on uterine leiomyoma showed that the leiomyoma size in premenopausal women who were administered daily $60 \mathrm{mg}$ doses of raloxifene over a 2-year period exhibited no change in leiomyoma size [61].

6.3. Adverse Events. Tamoxifen is not recommended for women with a prior history of deep venous thrombosis, pulmonary embolus, stroke, or transient ischemic attack because it increases the risk of ischemic stroke, particularly in women who are 50 years of age or older. Additionally, the risk of uterine/endometrial cancer was approximately doubled with tamoxifen use [62], and the risk of superficial thrombophlebitis was three times higher $[41,50]$. Some of these side effects could be explained by the inhibition of cellular glutamine uptake, oxidative stress, and the induction of apoptosis [63]. SERMs are seldom used for the treatment of uterine fibroids [52].

\section{Aromatase Inhibitors}

Aromatase inhibitors (AIs) significantly block both ovarian and peripheral estrogen production within 1 day of treatment [64]. Letrozole suppressed the production of estrogens, particularly estrone and estradiol, by $76-79 \%$ compared to their baseline levels [65]. The underlying mechanism is the inhibition of the aromatase enzyme, which is the enzyme that catalyzes the conversion of androgenic substances into estrogens [66]. Recent reports have suggested that aromatase is expressed to a greater extent in uterine leiomyoma tissues of African-American women compared to Caucasian women, which may contribute to the higher incidence of ULMs in African American women [67]. Aromatase inhibitors have been shown to be effective against fibroids in limited short term studies with dosing regimens that included $2.5 \mathrm{mg}$ per day of letrozole and $1 \mathrm{mg}$ per day of anastrozole [68]. One of the major concerns with the use of aromatase inhibitors is the reported bone loss with prolonged use, which necessitates the concomitant use of oral contraceptive pills or progesterone [69]. A recently published RCT compared the effects of three months of aromatase inhibitor (letrozole) to that of three months of gonadotropin-releasing hormone agonist (triptorelin) on uterine leiomyoma volume and hormonal status [70]. The results showed an advantage of the rapid onset of action of AIs in addition to the avoidance of the flare ups that initially occurs with GnRHa. Both treatment options induced significant shrinkage of the uterine fibroids and improvement in leiomyoma-associated symptoms [70]. The mean reduction of leiomyoma volume with 3-month use of anastrozole is $55.7 \%$ [71]. The authors suggested that aromatase inhibitors should be considered in women with fibroids on a short-term basis or in women who want to avoid surgical intervention to preserve their potential fertility [72]. Another concern with the use of AIs as a treatment option for uterine leiomyoma is its off-label use, which mandates a thorough review with patients prior to the initiation of the therapy [69]. Several RCTs are underway that would 
hopefully add to our understanding of the potential promising role of AIs in the treatment of uterine leiomyomas [62].

\section{Antiprogesterones}

Estrogen has traditionally been considered to be the most important stimulus for leiomyoma growth and numerous studies that included cell culture and animal models supported this concept [73]. Surprisingly, recent findings suggest that volume maintenance and growth of human ULMs are also heavily progesterone dependent, and hence antiprogesterone could reverse leiomyoma growth effects $[74,75]$. One potential link between the effects of the two key steroid hormones on ULMs is that estradiol induced the expression of the progesterone receptor and supported progesterone action on leiomyoma tissue [73]. Clinical findings also support these laboratory observations; studies have involved the evaluation of mifepristone (RU 486) [76-78], azoprisnil [68, 75], and, more recently, CDB-2914 and CDB-4124 (CDB: Contraceptive Development Branch) [79].

8.1. Mifepristone. Mifepristone (RU486), a well-known oral antiprogesterone compound, has been used for more than 20 years for multiple clinical indications [70, 80-82]. It has recently been evaluated as a potential therapeutic agent for uterine fibroids with a dose that ranges from $5 \mathrm{mg}$ to $50 \mathrm{mg}$ over a 3-month period [83-85]. Mifepristone reduced leiomyoma size $(26 \%$ to $74 \%)$ and improved leiomyoma related symptoms ( $63 \%$ to $100 \%$ induction of amenorrhea). Reported side effects included transient elevations in transaminases, which occurred in $4 \%$ of cases as well as endometrial hyperplasia and was detected in $28 \%$ of the women who were screened with endometrial biopsies [86]. However, these studies were mostly preliminary with limited numbers of subjects, and therefore, larger randomized well-controlled trials that include thorough monitoring of liver function and endometrial histology are required to conclusively determine the safety and efficacy of this treatment modality.

8.2. Asoprisnil. Asoprisnil (J867, BAY86-5294) is an investigational selective progesterone receptor modulator (SPRM) that was developed for the treatment of progesterone-sensitive myomata. It induces unique morphological changes and is associated with inhibited proliferation of the endometrium and leiomyomata. These changes may lead to amenorrhea, which is usually encountered with its use $[68,87,88]$. Asoprisnil is a tissue selective molecule that binds to the progesterone receptors with a threefold greater affinity than endogenous progesterone [83]. It reduces the uterine and leiomyoma volumes in a dose-dependent manner while achieving remarkable decreases in menorrhagia scores in women with menorrhagia [89]. Amenorrhea rates also increased as the dose of asoprisnil was increased $[84,87]$. When asoprisnil was administered daily for longer than 3-4 months, significant endometrial thickening and unusual histological appearance of the endometrial glands occurred [85].

8.3. Telapristone Acetate/CDB-4124 (Proposed Trade Names, Proellex, Progenta). CDB-4124 is another SPRM, but it is a relatively pure progesterone antagonist. It was studied in recent years for the treatment of uterine fibroids and is still being evaluated to address its safety and dose parameters in premenopausal women [90]. Limited information or publications are currently available on the various clinical trials that have investigated CDB-4124; these studies have either been completed or were terminated due to adverse liverrelated events according to the http://www.clinicaltrials.gov/ website. New clinical trials using lower doses of CDB-4124 have recently been approved by the FDA.

8.4. Ulipristal/CDB-2914 (VA 2914, EllaOne, Ella). Ulipristal is an FDA-approved selective progesterone receptor modulator (SPRM) that is indicated for emergency contraception. It is structurally similar to mifepristone and seems to be effective in the treatment of uterine fibroids. It is associated with a reduction in pain, bleeding, and leiomyoma size between 17 and 24\% [91], as well as an improvement in quality of life [92]. However, data on long-term treatment are lacking, and similar to other SPRMs, ulipristal may be associated with endometrial thickening and endometrial hyperplasia $[85,93,94]$. Large randomized well-controlled clinical trials are needed to evaluate the utility of ulipristal for potential clinical treatment of uterine fibroids [93].

\section{Somatostatin Analogues}

Increasing evidence has demonstrated a role for growth factors, such as insulin growth factor I (IGF-I) and IGF-II, in the initiation and progression of uterine fibroids [95-98]. Leiomyoma tissue expresses higher levels of IGF-I/IGF-II receptors compared to normal adjacent myometrium [89, 97]. Additionally, these tissues secrete their own IGF-1, probably for autocrine and paracrine use [98]. From a clinical perspective, it has been recently reported that patients with high levels of growth hormone (acromegalic patients) have a higher prevalence of uterine fibroids than the general population [99]. Lanreotide, which is a long-acting somatostatin analogue that has been shown to reduce growth hormone secretion, has also recently been evaluated in seven women with uterine fibroids in Italy [100]. Interestingly, lanreotide induced a $42 \%$ mean myoma volume reduction within a 3-month period. These results show that somatostatin analogues may potentially be a new therapy for uterine fibroids [101]. The treatment with somatostatin analogues for diseases other than leiomyoma appears to be safe and is usually well tolerated with some reports of gallstone formation $[102,103]$. However, the lacking of clinical trials which test the long-term use of somatostatin analogues along with the severe and adverse health implications such as decreased life expectancy due to accelerated heart disease observed in adults with growth hormone deficiency may hinder its future use for leiomyoma treatment.

\section{Cabergoline}

Carbergoline is a well-known dopamine agonist that is effectively used in the treatment of prolactinoma and for 
the inhibition of lactation. A recent study [104] evaluated carbergoline as a therapeutic option for uterine fibroids. The rational for such an approach lies in its effect as an inhibitory agent on GnRH release. A group in Iran published a preliminary study in 2007 [104] that favored the use of carbergoline as a medical treatment of uterine fibroids on which they reported a volume reduction of about $50 \%$ with 6 -week use [92]. The same group performed a subsequent study that compared carbergoline with diphereline, which is a gonadotropin-releasing hormone agonist [105]. They reported comparable results in terms of the shrinkage of the fibroids and the improvement in the sonographic, clinical, and intraoperative outcomes [105]. These findings warrant future larger controlled trials to clearly assess the potential use of carbergoline in the treatment of uterine fibroids.

\section{Danazol}

Danazol is a synthetic steroid that inhibits steroidogenesis through multienzymatic actions in addition to its suppressor effect on sex hormone binding globulin [106]. It reportedly induced a significant $24 \%$ volume reduction $[107,108]$. However, a recent Cochrane study failed to identify any randomized controlled trials that compared danazol to placebo or any other medical therapy in women with uterine fibroids [109].

\section{Gestrinone}

Gestrinone is a steroid that possesses antiestrogen receptor and antiprogesterone receptor properties in various tissues, including the endometrium [110]. A recent report from Italy evaluated the use of Gestrinone in the treatment of premenopausal women with uterine fibroids at a dose of $2.5 \mathrm{mg}$ twice per week over a 6-month period [110]. The authors reported a $32 \% \pm 10 \%$ reduction in uterine volume [110]. A subsequent study reported up to $60 \%$ leiomyoma shrinkage in size [111]. Gestrinone is a contraceptive agent and also exhibits several unfavorable side effects, such as mild androgenicity, weight gain, seborrhea, acne, hirsutism, and occasional hoarseness.

\section{Disclosure}

Dr. A. Al-Hendy was a site principal investigator in phase III clinical trials of "Azoprisnil" and "Pro-ellex". Dr. Mohamed Sabry has nothing to disclose.

\section{Acknowledgement}

The authors acknowledge NIH grant award R01HD04622808 to AA. They also thank Dr. Veera Rajaratnam for the expertise rendered in editing and revising the paper.

\section{References}

[1] E. A. Stewart, "Uterine fibroids," Lancet, vol. 357, no. 9252, pp. 293-298, 2001.
[2] S. Sankaran and I. T. Manyonda, "Medical management of fibroids," Best Practice and Research: Clinical Obstetrics and Gynaecology, vol. 22, no. 4, pp. 655-676, 2008.

[3] W. H. Parker, "Etiology, symptomatology, and diagnosis of uterine myomas," Fertility and Sterility, vol. 87, no. 4, pp. 725-736, 2007.

[4] J. S. Drinville and S. Memarzadeh, "Benign Disorders of the Uterine Corpus," in CURRENT Diagnosis \& Treatment Obstetrics \& Gynecology, A. H. DeCherney, Ed., McGraw-Hill, 10th edition, 2010.

[5] T. M. Roth, T. Gustilo-Ashby, M. D. Barber, and E. R. Myers, "Effects of race and clinical factors on short-term outcomes of abdominal myomectomy," Obstetrics and Gynecology, vol. 101, no. 5, pp. 881-884, 2003.

[6] E.-E. R. Othman and A. Al-Hendy, "Molecular genetics and racial disparities of uterine leiomyomas," Best Practice and Research: Clinical Obstetrics and Gynaecology, vol. 22, no. 4, pp. 589-601, 2008.

[7] J. T. Witherspoon, "The etiology of uterine fibroids, with special reference to the frequency of their occurrence in the Negro: an hypothesis," Surgery Gynecology And Obstetrics, vol. 58 , p. 4, 1934.

[8] R. Torpin, E. Pund, and W. J. Peeples, "The etiologic and pathologic factors in a series of 1,741 fibromyomas of the uterus," American Journal of Obstetrics and Gynecology, vol. 44, no. 4, pp. 569-574, 1942.

[9] L. S. Wilcox, L. M. Koonin, R. Pokras, L. T. Strauss, Z. Xia, and H. B. Peterson, "Hysterectomy in the United States, 1988-1990," Obstetrics and Gynecology, vol. 83, no. 4, pp. 549-555, 1994.

[10] F. Amant, E. Huys, A. Geurts-Moespot et al., "Ethnic variations in uterine leiomyoma biology are not caused by differences in myometrial estrogen receptor alpha levels," Journal of the Society for Gynecologic Investigation, vol. 10, no. 2, pp. 105-109, 2003.

[11] P. B. Bach, D. Schrag, O. W. Brawley, A. Galaznik, S. Yakren, and C. B. Begg, "Survival of blacks and whites after a cancer diagnosis," Journal of the American Medical Association, vol. 287, no. 16, pp. 2106-2113, 2002.

[12] S. K. Sunkara, M. Khairy, T. El-Toukhy, Y. Khalaf, and A. Coomarasamy, "The effect of intramural fibroids without uterine cavity involvement on the outcome of IVF treatment: a systematic review and meta-analysis," Human Reproduction, vol. 25, no. 2, pp. 418-429, 2010.

[13] E. R. Cardozo, J. H. Segars, N. K. Banks, M. B. Henne, B. J. Stregman, and J. H. Segars, "The estimated annual cost of uterine leiomyomata in the United States," American Journal of Obstetrics and Gynecology. In press.

[14] Y. Zhang, W. Peng, J. Clarke, and Z. Liu, "Acupuncture for uterine fibroids," Cochrane Database of Systematic Reviews, no. 1, Article ID CD007221, 2010.

[15] M. Viswanathan, K. Hartmann, N. McKoy et al., "Management of uterine fibroids: an update of the evidence," Evidence report/technology assessment, no. 154, pp. 1-122, 2007.

[16] C. Sharan, S. K. Halder, C. Thota, T. Jaleel, S. Nair, and A. AlHendy, "Vitamin D inhibits proliferation of human uterine leiomyoma cells via catechol-O-methyltransferase," Fertility and Sterility, vol. 95, no. 1, pp. 247-253, 2011.

[17] S. K. Halder, J. S. Goodwin, and A. Al-Hendy, "1,25-Dihydroxyvitamin D3 reduces TGF- $\beta 3$-induced fibrosis-related gene expression in human uterine leiomyoma cells," Journal of Clinical Endocrinology and Metabolism, vol. 96, no. 4, pp. E754-E762, 2011. 
[18] C. Sharan, S. K. Halder, C. Thota, T. Jaleel, S. Nair, and A. AlHendy, "Vitamin D inhibits proliferation of human uterine leiomyoma cells via catechol-O-methyltransferase," Fertility and Sterility, vol. 95, no. 1, pp. 247-253, 2011.

[19] S. K. Halder, C. Sharan, and A. Al-Hendy, "Vitamin D treatment induces dramatic shrinkage of uterine leiomyomas growth in the Eker rat model," Fertility and Sterility, vol. 94, no. 4, pp. S75-S76, 2010.

[20] M. Bläuer, P. H. Rovio, T. Ylikomi, and P. K. Heinonen, "Vitamin D inhibits myometrial and leiomyoma cell proliferation in vitro," Fertility and Sterility, vol. 91, no. 5, pp. 1919-1925, 2009.

[21] S. K. Halder, S. Goodwin, and A. Al-Hendy, "Vitamin D exhibits antiestrogenic effects in human uterine leiomyoma cells," Fertility and Sterility, vol. 94, no. 4, pp. S219-S220, 2010.

[22] S. K. Halder et al., "1, 25 dihydroxyvitamin D3 disorganizes actin fibers in human immortalized uterine leiomyoma cells," Fertility and Sterility, vol. 92, no. 3, pp. S127-S128, 2009.

[23] M.S. Abdelraheem and A. Al-Hendy, "Serum vitamin D3 level inversely correlates with total fibroid tumor burden in women with symptomatic uterine fibroid," Fertility and Sterility, vol. 94, no. 4, p. S74, 2010.

[24] N. Khan and H. Mukhtar, "Tea polyphenols for health promotion," Life Sciences, vol. 81, no. 7, pp. 519-533, 2007.

[25] S. Kuriyama, T. Shimazu, K. Ohmori et al., "Green tea consumption and mortality due to cardiovascular disease, cancer, and all causes in Japan: the Ohsaki study," Journal of the American Medical Association, vol. 296, no. 10, pp. 12551265, 2006.

[26] J. D. Lambert and C. S. Yang, "Cancer chemopreventive activity and bioavailability of tea and tea polyphenols," Mutation Research, vol. 523-524, pp. 201-208, 2003.

[27] J. E. Chung, M. Kurisawa, Y. J. Kim, H. Uyama, and S. Kobayashi, "Amplification of antioxidant activity of catechin by polycondensation with acetaldehyde," Biomacromolecules, vol. 5, no. 1, pp. 113-118, 2004.

[28] J. K. Lin, Y. C. Liang, and S. Y. Lin-Shiau, "Cancer chemoprevention by tea polyphenols through mitotic signal transduction blockade," Biochemical Pharmacology, vol. 58, no. 6, pp. 911-915, 1999.

[29] T. L. Zern, R. J. Wood, C. Greene et al., "Grape polyphenols exert a cardioprotective effect in pre- and postmenopausal women by lowering plasma lipids and reducing oxidative stress," Journal of Nutrition, vol. 135, no. 8, pp. 1911-1917, 2005.

[30] H. Mukhtar and N. Ahmad, "Green tea in chemoprevention of cancer," Toxicological Sciences, vol. 52, no. 2, pp. 111-117, 1999.

[31] N. Khan, F. Afaq, M. Saleem, N. Ahmad, and H. Mukhtar, "Targeting multiple signaling pathways by green tea polyphenol (-)-epigallocatechin-3-gallate," Cancer Research, vol. 66, no. 5, pp. 2500-2505, 2006.

[32] D. Zhang, M. Al-Hendy, G. Richard-Davis, V. MontgomeryRice, V. Rajaratnam, and A. Al-Hendy, "Antiproliferative and proapoptotic effects of epigallocatechin gallate on human leiomyoma cells," Fertility and Sterility, vol. 94, no. 5, pp. 1887-1893, 2010.

[33] D. Zhang, M. Al-Hendy, G. Richard-Davis, V. MontgomeryRice, V. Rajaratnam, and A. Al-Hendy, "Antiproliferative and proapoptotic effects of epigallocatechin gallate on human leiomyoma cells," Fertility and Sterility, vol. 94, no. 5, pp. 1887-1893, 2010.
[34] N. Ahmad, P. Cheng, and H. Mukhtar, "Cell cycle dysregulation by green tea polyphenol epigallocatechin-3-gallate," Biochemical and Biophysical Research Communications, vol. 275, no. 2, pp. 328-334, 2000.

[35] C. Chen, R. Yu, E. D. Owuor, and A. N. Tony Kong, "Activation of antioxidant-response element (ARE), mitogen-activated protein kinases (MAPKs) and caspases by major green tea polyphenol components during cell survival and death," Archives of Pharmacal Research, vol. 23, no. 6, pp. 605-612, 2000.

[36] S. Gupta, N. Ahmad, A. L. Nieminen, and H. Mukhtar, "Growth inhibition, cell-cycle dysregulation, and induction of apoptosis by green tea constituent (-)-epigallocatechin-3gallate in androgen-sensitive and androgen-insensitive human prostate carcinoma cells," Toxicology and Applied Pharmacology, vol. 164, no. 1, pp. 82-90, 2000.

[37] Y. Tang, D. Y. Zhao, S. Elliott et al., "Epigallocatechin-3 gallate induces growth inhibition and apoptosis in human breast cancer cells through survivin suppression," International Journal of Oncology, vol. 31, no. 4, pp. 705-711, 2007.

[38] P. Broqua, P. J. M. Riviere, P. Michael Conn, J. E. Rivier, M. L. Aubert, and J. L. Junien, "Pharmacological profile of a new, potent, and long-acting gonadotropin-releasing hormone antagonist: degarelix," Journal of Pharmacology and Experimental Therapeutics, vol. 301, no. 1, pp. 95-102, 2002.

[39] M. P. Samant, D. J. Hong, G. Croston, C. Rivier, and J. Rivier, "Novel gonadotropin-releasing hormone antagonists with substitutions at position 5," Biopolymers, vol. 80, no. 2-3, pp. 386-391, 2005.

[40] D. Gonzalez-Barcena, R. B. Alvarez, E. P. Ochoa et al., "Treatment of uterine leiomyomas with luteinizing hormone-releasing hormone antagonist Cetrorelix," Human Reproduction, vol. 12, no. 9, pp. 2028-2035, 1997.

[41] B. Ettinger, D. M. Black, B. H. Mitlak et al., "Reduction of vertebral fracture risk in postmenopausal women with osteoporosis treated with raloxifene: results from a 3-year randomized clinical trial," Journal of the American Medical Association, vol. 282, no. 7, pp. 637-645, 1999.

[42] "Deal watch: Abbott and Neurocrine to develop promising endometriosis drug," Nature Reviews Drug Discovery, vol. 9, no. 8 , p. $584,2010$.

[43] C. Chen, D. Wu, Z. Guo et al., "Discovery of sodium R-(+)-42-[5-(2-Fluoro-3-methoxyphenyl)-3-(2-fluoro-6- [trifluoromethyl]-benzyl)-4-methyl-2,6-dioxo-3,6-dihydro-2H-pyrimidin-1-yl] -1-phenylethylaminobutyrate (elagolix), a potent and orally available nonpeptide antagonist of the human gonadotropin-releasing hormone receptor," Journal of $\mathrm{Me}$ dicinal Chemistry, vol. 51, no. 23, pp. 7478-7485, 2008.

[44] Abbott, "Future abbott pipeline," 2011.

[45] W. Dmowski, "Advances in the treatment of endometriosisthe potential of Elagolix," US Obstetrics \& Gynecology, vol. 3, no. 1, pp. 21-23, 2008.

[46] R. S. Struthers, A. J. Nicholls, J. Grundy et al., "Suppression of gonadotropins and estradiol in premenopausal women by oral administration of the nonpeptide gonadotropin-releasing hormone antagonist elagolix," Journal of Clinical Endocrinology and Metabolism, vol. 94, no. 2, pp. 545-551, 2009.

[47] R. L. Barbieri, "Hormone treatment of endometriosis: the estrogen threshold hypothesis," American Journal of Obstetrics and Gynecology, vol. 166, no. 2, pp. 740-745, 1992.

[48] A. E. Lethaby and B. J. Vollenhoven, "An evidence-based approach to hormonal therapies for premenopausal women with fibroids," Best Practice and Research: Clinical Obstetrics and Gynaecology, vol. 22, no. 2, pp. 307-331, 2008. 
[49] L. J. Black, M. Sato, E. R. Rowley et al., "Raloxifene (LY139481 $\mathrm{HCl}$ ) prevents bone loss and reduces serum cholesterol without causing uterine hypertrophy in ovariectomized rats," Journal of Clinical Investigation, vol. 93, no. 1, pp. 63-69, 1994.

[50] S. Temin, "American Society of Clinical Oncology clinical practice guideline update on the use of pharmacologic interventions including tamoxifen, raloxifene, and aromatase inhibition for breast cancer risk reduction," Gynecologic Oncology, vol. 115, no. 1, pp. 132-134, 2009.

[51] B. Fisher, J. P. Costantino, C. K. Redmond, E. R. Fisher, D. L. Wickerham, and W. M. Cronin, "Endometrial cancer in tamoxifen-treated breast cancer patients: findings from the National Surgical Adjuvant Breast and Bowel Project (NSABP) B-14," Journal of the National Cancer Institute, vol. 86, no. 7, pp. 527-537, 1994.

[52] X. Lingxia, W. Taixiang, and C. Xiaoyan, "Selective estrogen receptor modulators (SERMs) for uterine leiomyomas," Cochrane Database of Systematic Reviews, no. 2, Article ID CD005287, 2007.

[53] M. Zbucka, W. Miltyk, T. Bielawski, A. Surazynski, J. Palka, and S. Wolczynski, "Mechanism of collagen biosynthesis upregulation in cultured leiomyoma cells," Folia Histochemica et Cytobiologica, vol. 45, supplement 1, pp. 181-185, 2007.

[54] C. Becker, "Another selective estrogen-receptor modulator for osteoporosis," New England Journal of Medicine, vol. 362, no. 8, pp. 752-754, 2010.

[55] "Lasofoxifene: new drug. Osteoporosis: no better than raloxifene," Prescrire International, vol. 18, no. 104, p. 247, 2009.

[56] B. H. Mitlak and F. J. Cohen, "In search of optimal longterm female hormone replacement: the potential of selective estrogen receptor modulators," Hormone Research, vol. 48, no. 4, pp. 155-163, 1997.

[57] M. Dutertre and C. L. Smith, "Molecular mechanisms of selective estrogen receptor modulator (SERM) action," Journal of Pharmacology and Experimental Therapeutics, vol. 295, no. 2, pp. 431-437, 2000.

[58] T. I. Richardson, S. A. Frank, M. Wang et al., "Structureactivity relationships of SERMs optimized for uterine antagonism and ovarian safety," Bioorganic and Medicinal Chemistry Letters, vol. 17, no. 13, pp. 3544-3549, 2007.

[59] S. Palomba, A. Sammartino, C. Di Carlo, P. Affinito, F. Zullo, and C. Nappi, "Effects of raloxifene treatment on uterine leiomyomas in postmenopausal women," Fertility and Sterility, vol. 76, no. 1, pp. 38-43, 2001.

[60] S. Palomba, F. Orio, T. Russo et al., "Antiproliferative and proapoptotic effects of raloxifene on uterine leiomyomas in postmenopausal women," Fertility and Sterility, vol. 84, no. 1, pp. 154-161, 2005.

[61] A. Premkumar, D. J. Venzon, N. Avila et al., "Gynecologic and hormonal effects of raloxifene in premenopausal women," Fertility and Sterility, vol. 88, no. 6, pp. 1637-1644, 2007.

[62] "Aromatase Inhibitors for Treatment of Uterine Leiomyomas. Clinical Trials.gov," 2010, http://clinicaltrials.gov/ct2/show/ NCT00945360?term=aromatase+inhibitors++fibroid\& rank $=1$.

[63] V. K. Todorova, Y. Kaufmann, S. Luo, and V. Suzanne Klimberg, "Tamoxifen and raloxifene suppress the proliferation of estrogen receptor-negative cells through inhibition of glutamine uptake," Cancer Chemotherapy and Pharmacology, vol. 67, no. 2, pp. 285-291, 2011.

[64] ACOG practice bulletin, "Alternatives to hysterectomy in the management of leiomyomas," Obstetrics \& Gynecology, vol. 112, no. 2, pp. 387-400, 2008.
[65] T. J. Iveson, I. E. Smith, J. Ahern, D. A. Smithers, P. F. Trunet, and M. Dowsett, "Phase I study of the oral nonsteroidal aromatase inhibitor CGS 20267 in healthy postmenopausal women," Journal of Clinical Endocrinology and Metabolism, vol. 77, no. 2, pp. 324-331, 1993.

[66] I. E. Smith and M. Dowsett, "Aromatase inhibitors in breast cancer," New England Journal of Medicine, vol. 348, no. 24, pp. 2431-2442, 2003.

[67] H. Ishikawa, S. Reierstad, M. Demura et al., "High aromatase expression in uterine leiomyoma tissues of African-American women," Journal of Clinical Endocrinology and Metabolism, vol. 94, no. 5, pp. 1752-1756, 2009.

[68] A. R. W. Williams, H. O. D. Critchley, J. Osei et al., "The effects of the selective progesterone receptor modulator asoprisnil on the morphology of uterine tissues after 3 months treatment in patients with symptomatic uterine leiomyomata," Human Reproduction, vol. 22, no. 6, pp. 1696-1704, 2007.

[69] M. A. Bedaiwy and J. Liu, "Long-term management of endometriosis: medical therapy and treatment of infertility," Sexuality, Reproduction and Menopause, vol. 8, no. 3, pp. 10-14, 2010.

[70] D. T. Baird, A. Brown, L. Cheng et al., "Mifepristone: a novel estrogen-free daily contraceptive pill," Steroids, vol. 68, no. 10-13, pp. 1099-1105, 2003.

[71] F. K. Varelas, A. N. Papanicolaou, N. Vavatsi-Christaki, G. A. Makedos, and G. D. Vlassis, "The effect of anastrazole on symptomatic uterine leiomyomata," Obstetrics and Gynecology, vol. 110, no. 3, pp. 643-649, 2007.

[72] M. E. Parsanezhad, M. Azmoon, S. Alborzi et al., "A randomized, controlled clinical trial comparing the effects of aromatase inhibitor (letrozole) and gonadotropin-releasing hormone agonist (triptorelin) on uterine leiomyoma volume and hormonal status," Fertility and Sterility, vol. 93, no. 1, pp. 192-198, 2010.

[73] H. Ishikawa, K. Ishi, V. Ann Serna, R. Kakazu, S. E. Bulun, and T. Kurita, "Progesterone is essential for maintenance and growth of uterine leiomyoma," Endocrinology, vol. 151, no. 6, pp. 2433-2442, 2010.

[74] S. Yoshida, N. Ohara, Q. Xu et al., "Cell-type specific actions of progesterone receptor modulators in the regulation of uterine leiomyoma growth," Seminars in Reproductive Medicine, vol. 28, no. 3, pp. 260-273, 2010.

[75] J. Wilkens, K. Chwalisz, C. Han et al., "Effects of the selective progesterone receptor modulator asoprisnil on uterine artery blood flow, ovarian activity, and clinical symptoms in patients with uterine leiomyomata scheduled for hysterectomy," Journal of Clinical Endocrinology and Metabolism, vol. 93, no. 12, pp. 4664-4671, 2008.

[76] J. L. Carbonell Esteve, R. Acosta, B. Heredia, Y. Pérez, M. C. Y. Castañeda, and A. V. Hernández, "Mifepristone for the treatment of uterine leiomyomas: a randomized controlled trial," Obstetrics and Gynecology, vol. 112, no. 5, pp. 1029-1036, 2008.

[77] K. Fiscella, S. H. Eisinger, S. Meldrum, C. Feng, S. G. Fisher, and D. S. Guzick, "Effect of mifepristone for symptomatic leiomyomata on quality of life and uterine size: a randomized controlled trial," Obstetrics and Gynecology, vol. 108, no. 6, pp. 1381-1387, 2006.

[78] M. Engman, S. Granberg, A. R. W. Williams, C. X. Meng, P. G. L. Lalitkumar, and K. Gemzell-Danielsson, "Mifepristone for treatment of uterine leiomyoma. A prospective randomized placebo controlled trial," Human Reproduction, vol. 24, no. 8, pp. 1870-1879, 2009. 
[79] B. J. Attardi, J. Burgenson, S. A. Hild, and J. R. Reel, "In vitro antiprogestational/antiglucocorticoid activity and progestin and glucocorticoid receptor binding of the putative metabolites and synthetic derivatives of CDB-2914, CDB4124, and mifepristone," Journal of Steroid Biochemistry and Molecular Biology, vol. 88, no. 3, pp. 277-288, 2004.

[80] M. Engman, L. Skoog, G. Söderqvist, and K. GemzellDanielsson, "The effect of mifepristone on breast cell proliferation in premenopausal women evaluated through fine needle aspiration cytology," Human Reproduction, vol. 23, no. 9, pp. 2072-2079, 2008.

[81] P. G. L. Lalitkumar, S. Lalitkumar, C. X. Meng et al., "Mifepristone, but not levonorgestrel, inhibits human blastocyst attachment to an in vitro endometrial three-dimensional cell culture model," Human Reproduction, vol. 22, no. 11, pp. 3031-3037, 2007.

[82] N. C. Sharts-Engel, "The RU 486 story: the French experience," The American Journal of Maternal Child Nursing, vol. 17 , no. 1, p. 56, 1992.

[83] P. K. Brahma, K. M. Martel, and G. M. Christman, "Future directions in myoma research," Obstetrics and Gynecology Clinics of North America, vol. 33, no. 1, pp. 199-224, 2006.

[84] K. Chwalisz, R. Garg, R. Brenner, O. Slayden, C. Winkel, and W. Elger, "Role of nonhuman primate models in the discovery and clinical development of selective progesterone receptor modulators (SPRMs)," Reproductive Biology and Endocrinology, vol. 4, supplement 1, p. S8, 2006.

[85] I. M. Spitz, "Clinical utility of progesterone receptor modulators and their effect on the endometrium," Current Opinion in Obstetrics and Gynecology, vol. 21, no. 4, pp. 318-324, 2009.

[86] J. Steinauer, E. A. Pritts, R. Jackson, and A. F. Jacoby, "Systematic review of mifepristone for the treatment of uterine leiomyomata," Obstetrics and Gynecology, vol. 103, no. 6, pp. 1331-1336, 2004.

[87] K. Chwalisz, L. Larsen, C. Mattia-Goldberg, A. Edmonds, W. Elger, and C. A. Winkel, "A randomized, controlled trial of asoprisnil, a novel selective progesterone receptor modulator, in women with uterine leiomyomata," Fertility and Sterility, vol. 87, no. 6, pp. 1399-1412, 2007.

[88] K. Chwalisz, W. Elger, T. Stickler, C. Mattia-Goldberg, and L. Larsen, "The effects of 1-month administration of asoprisnil (J867), a selective progesterone receptor modulator, in healthy premenopausal women," Human Reproduction, vol. 20, no. 4, pp. 1090-1099, 2005.

[89] K. D. Boehm, M. Daimon, I. G. Gorodeski, L. A. Sheean, W. H. Utian, and J. Ilan, "Expression of the insulin-like and platelet-derived growth factor genes in human uterine tissues," Molecular Reproduction and Development, vol. 27, no. 2, pp. 93-101, 1990.

[90] "Determination of the Lowest, Safe and Effective Dose of the Anti-Progestin, Proellex, in Healthy Women. Clinical Trials 2010 September," http://clinicaltrials.gov/ct2/show/ NCT01187043?term=proellex\&rank=17.

[91] L. K. Nieman, W. Blocker, T. Nansel et al., "Efficacy and tolerability of CDB-2914 treatment for symptomatic uterine fibroids: a randomized, double-blind, placebo-controlled, phase IIb study," Fertility and Sterility, vol. 95, no. 2, pp. 767772.e2, 2011.

[92] M. S. Melli, L. Farzadi, and E. O. S. Madarek, "Comparison of the effect of gonadotropin-releasing hormone analog (Diphereline) and Cabergoline (Dostinex) treatment on uterine myoma regression," Saudi Medical Journal, vol. 28, no. 3, pp. 445-450, 2007.
[93] K. Fiscella and S. Eisinger, "CDB-2914 for uterine leiomyomata treatment: a randomized controlled trial," Obstetrics and Gynecology, vol. 112, no. 3, p. 707, 2008.

[94] E. D. Levens, C. Potlog-Nahari, A. Y. Armstrong et al., "CDB2914 for uterine leiomyomata treatment: a randomized controlled trial," Obstetrics and Gynecology, vol. 111, no. 5, pp. 1129-1136, 2008.

[95] J. W. Höppener, S. Mosselman, P. J. Roholl et al., "Expression of insulin-like growth factor-I and -II genes in human smooth muscle tumours," EMBO Journal, vol. 7, no. 5, pp. 1379-1385, 1988.

[96] T. Gloudemans, I. Prinsen, J. A. M. Van Unnik, C. J. M. Lips, W. Den Otter, and J. S. Sussenbach, "Insulin-like growth factor gene expression in human smooth muscle tumors," Cancer Research, vol. 50, no. 20, pp. 6689-6695, 1990.

[97] G. Norstedt, A. Levinovitz, and H. Eriksson, "Regulation of uterine insulin-like growth factor I mRNA and insulin-like growth factor II mRNA by estrogen in the rat," Acta Endocrinologica, vol. 120, no. 4, pp. 466-472, 1989.

[98] M. S. Rein, A. J. Friedman, M. R. Pandian, and L. J. Heffner, "The secretion of insulin-like growth factors I and II by explant cultures of fibroids and myometrium from women treated with a gonadotropin-releasing hormone agonist," Obstetrics and Gynecology, vol. 76, no. 3, pp. 388-394, 1990.

[99] O. Cohen, B. Schindel, and R. Homburg, "Uterine leiomyomata-a feature of acromegaly," Human Reproduction, vol. 13, no. 7, pp. 1945-1946, 1998.

[100] C. G. Nilsson, T. Luukkainen, J. Diaz, and H. Allonen, "Intrauterine contraception with levonorgestrel: a comparative randomised clinical performance study," Lancet, vol. 1, no. 8220, pp. 577-580, 1981.

[101] V. De Leo, A. Marca, G. Morgante, F. M. Severi, and F. Petraglia, "Administration of somatostatin analogue reduces uterine and myoma volume in women with uterine leiomyomata," Fertility and Sterility, vol. 75, no. 3, pp. 632-633, 2001.

[102] R. A. Feelders, L. J. Hofland, M. O. Van Aken et al., "Medical therapy of acromegaly: efficacy and safety of somatostatin analogues," Drugs, vol. 69, no. 16, pp. 2207-2226, 2009.

[103] P. H. Davies, S. E. Stewart, I. Lancranjan, M. C. Sheppard, and P. M. Stewart, "Long-term therapy with long-acting oc-

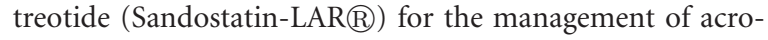
megaly," Clinical Endocrinology, vol. 48, no. 3, pp. 311-316, 1998.

[104] I. Sivin and J. Stern, "Health during prolonged use of levonorgestrel 20 micrograms/d and the copper TCu 380Ag intrauterine contraceptive devices: a multicenter study. International Committee for Contraception Research (ICCR)," Fertility and Sterility, vol. 61, no. 1, pp. 70-77, 1994.

[105] M. Sayyah-Melli, S. Tehrani-Gadim, A. Dastranj-Tabrizi et al., "Comparison of the effect of gonadotropin-releasing hormone agonist and dopamine receptor agonist on uterine myoma growth. Histologic, sonographic, and intra-operative changes," Saudi Medical Journal, vol. 30, no. 8, pp. 10241033, 2009.

[106] K. A. Steingold, J. K. H. Lu, H. L. Judd, and D. R. Meldrum, "Danazol inhibits steroidogenesis by the human ovary in vivo," Fertility and Sterility, vol. 45, no. 5, pp. 649-654, 1986.

[107] V. De Leo, A. La Marca, and G. Morgante, "Short-term treatment of uterine fibromyomas with danazol," Gynecologic and Obstetric Investigation, vol. 47, no. 4, pp. 258-262, 1999.

[108] A. La Marca, M. C. Musacchio, G. Morgante, F. Petraglia, and V. De Leo, "Hemodynamic effect of danazol therapy in women with uterine leiomyomata," Fertility and Sterility, vol. 79, no. 5, pp. 1240-1242, 2003. 
[109] L. Q. Ke, K. Yang, J. Li, and C. M. Li, "Danazol for uterine fibroids," Cochrane Database of Systematic Reviews, no. 3, Article ID CD007692, 2009.

[110] A. La Marca, S. Giulini, G. Vito, R. Orvieto, A. Volpe, and V. M. Jasonni, "Gestrinone in the treatment of uterine leiomyomata: effects on uterine blood supply," Fertility and Sterility, vol. 82, no. 6, pp. 1694-1696, 2004.

[111] E. M. Coutinho, "Treatment of large fibroids with high doses of gestrinone," Gynecologic and Obstetric Investigation, vol. 30, no. 1, pp. 44-47, 1990. 


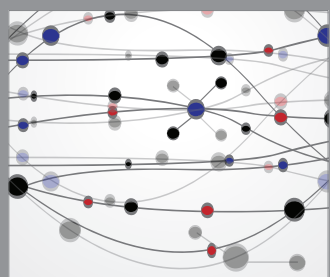

The Scientific World Journal
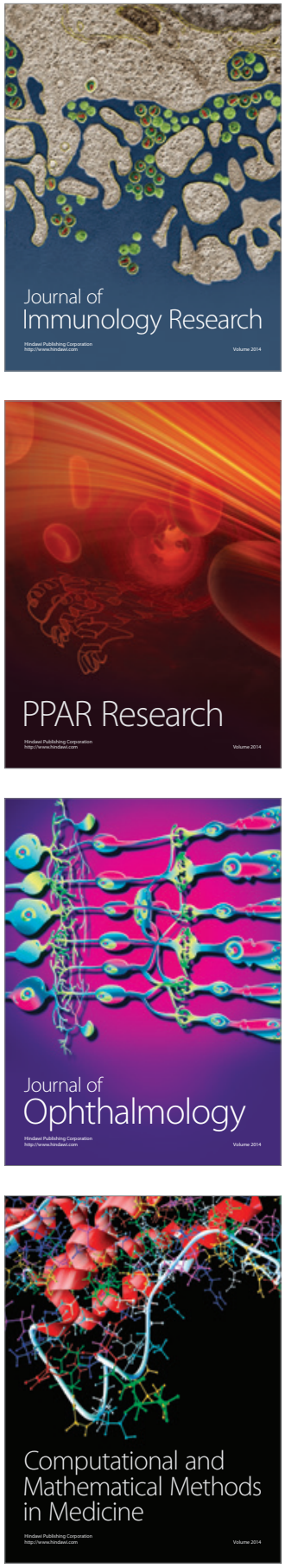

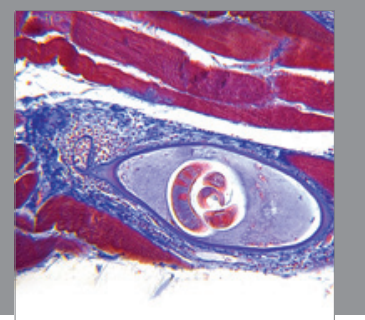

Gastroenterology

Research and Practice
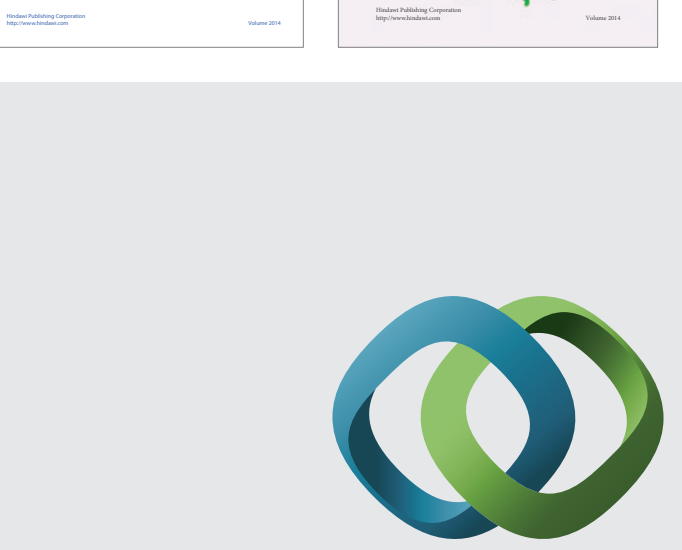

\section{Hindawi}

Submit your manuscripts at

http://www.hindawi.com
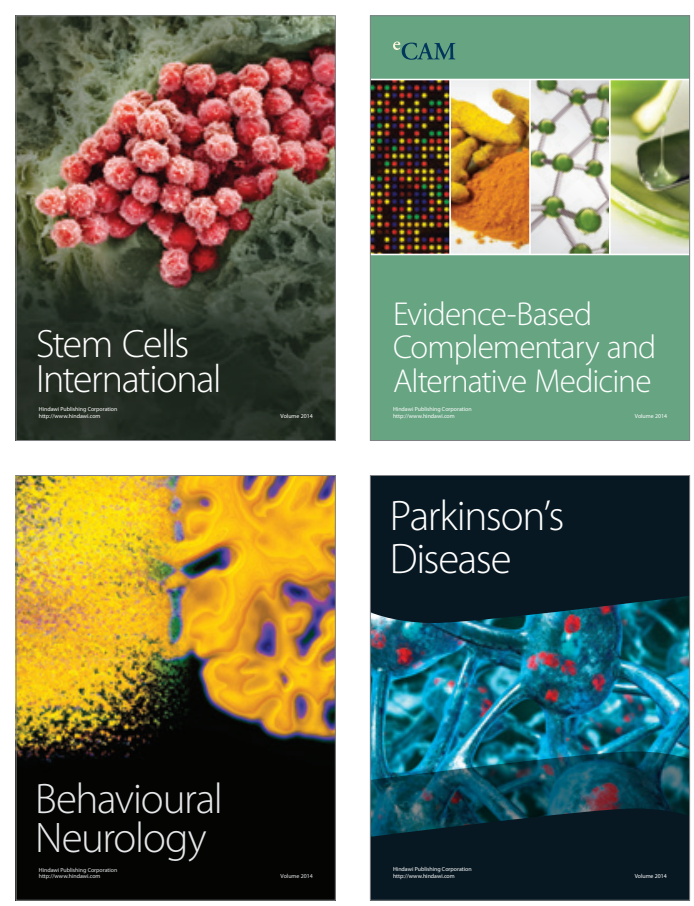

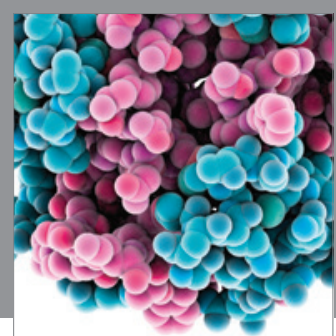

Journal of
Diabetes Research

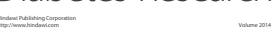

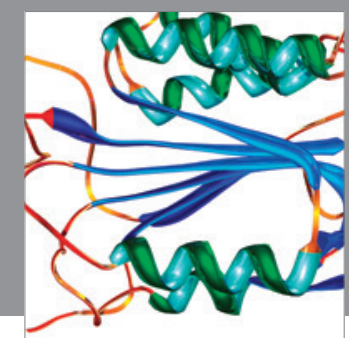

Disease Markers
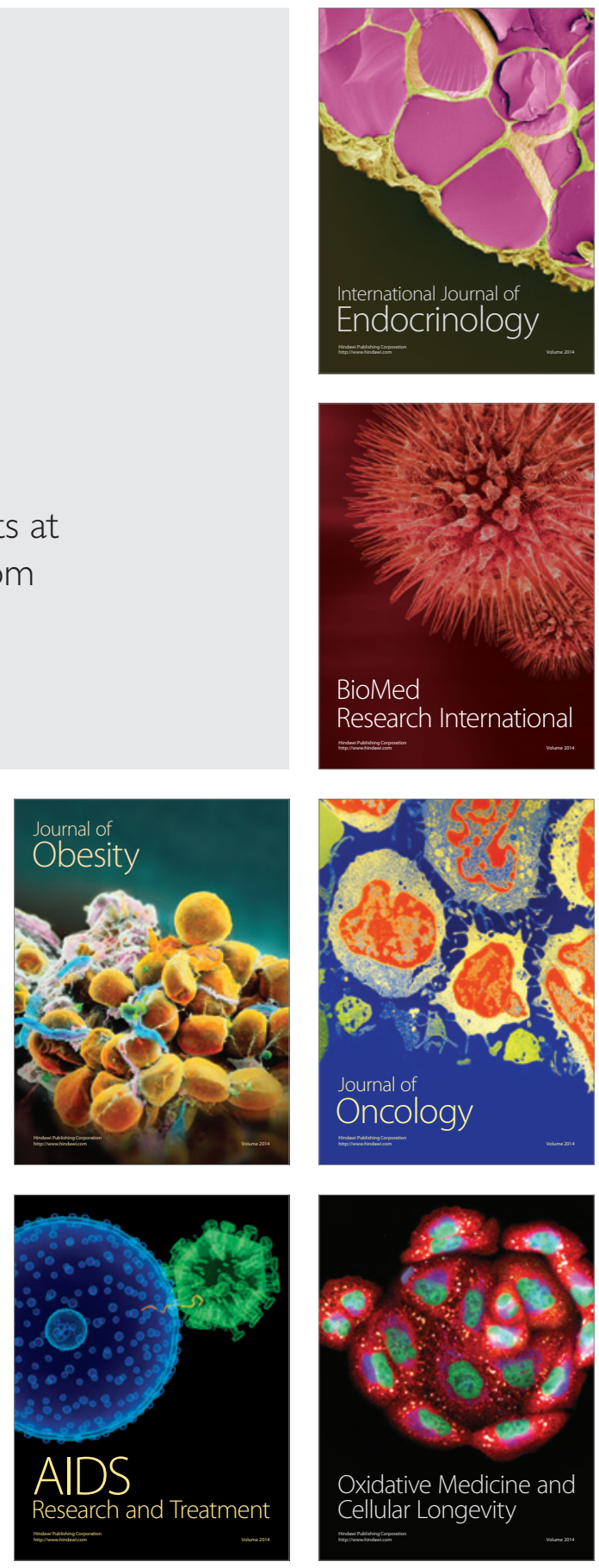